\title{
LYME BORRELIOSIS: CLINICAL MANIFESTATIONS AND ADVANCES IN DIAGNOSIS AND CONTROL
}

\author{
Sandip Kumar Khurana ${ }^{1 *}$ (D), Anju Sehrawat ${ }^{1}$ (D), Ruchi Tiwari ${ }^{2}$ (D), Khan $\operatorname{Sharun}^{3}$ (D), \\ Kuldeep Dhama ${ }^{4}$ (D), Rajneesh Rana ${ }^{5^{*}}$ (iD
}

${ }^{1}$ ICAR-Central Institute for Research on Buffaloes, Sirsa Road, Hisar, 125001, India

${ }^{2}$ Department of Veterinary Microbiology and Immunology, College of Veterinary Sciences, UP Pandit Deen Dayal Upadyaya Pashu Chikitsa Vigyan Vishwavidyalya Evam Go-Anusandhan Sansthan (DUVASU), Mathura 281001, Uttar Pradesh, India

${ }^{3}$ Division of Surgery, ICAR-Indian Veterinary Research Institute, Izatnagar, Bareilly-243 122, Uttar Pradesh, India

${ }^{4}$ Division of Pathology, ICAR-Indian Veterinary Research Institute, Izatnagar, Bareilly 243122, India

${ }^{5}$ Division of Bacteriology and Mycology, ICAR-Indian Veterinary Research Institute, Izatnagar, Bareilly 243122, India

Received - November 05, 2020; Revision - December 18, 2020; Accepted - December 20, 2020

Available Online - December 30, 2020

DOI: http://dx.doi.org/10.18006/2020.8(6).721.729

\section{KEYWORDS}

Lyme disease

Borrelia

Clinical manifestations

Diagnosis

\begin{abstract}
Lyme disease or borreliosis is presumed one of the most significant vector-borne diseases globally. The disease is re-emerging in numerous parts of world. It has expanded dramatically in newer areas in recent decades. Lyme disease is caused by Borrelia burgdorferi yet additionally by other borrelial species, $B$. afzelii and B. garini which cause diverse clinical syndromes. Spatial distribution and clinical presentations differ depending on the causative species. Clinical manifestations of Lyme disease can be delineated in three stages. The first stage is presented in the form of erythema migrans at the site of tick bite. Early dispersed stage can lead to multiple lesions of erythema migrans, neuroborreliosis, lymphocytoma, arthritis or carditis. The manifestation at later stage shows acordermatitis chronica atrophicans, arthritis and neurological involvement. Diagnosis is challenging owing the several clinical presentations and could require multiple tests. The antibiotics that are currently under use, help in the clearance of bacteria from the affected host and stop further spread of the disease. Although several antibiotics are being used for Lyme disease, doxycycline is the widely used antimicrobial in early stage of the disease. Several attempts have been made to develop a vaccine against Lyme disease, however, none of them have been successfully marketed. The present review discusses clinical manifestations, and advances in diagnosis and control of Lyme disease.
\end{abstract}

* Corresponding author

E-mail: sandipkk2003@yahoo.co.in (Sandip Kumar Khurana); rajneeshrana01@yahoo.com (Rajneesh Rana)

Peer review under responsibility of Journal of Experimental Biology and Agricultural Sciences.

Production and Hosting by Horizon Publisher India [HPI] (http://www.horizonpublisherindia.in/).

All rights reserved.
All the articles published by Journal of Experimental Biology and Agricultural Sciences are licensed under a Creative Commons Attribution-NonCommercial 4.0 International License Based on a work at www.jebas.org.

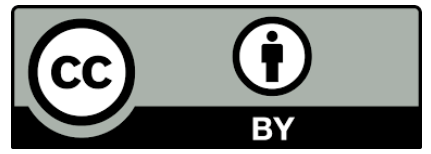




\section{Introduction}

The Lyme disease (LD) was initially found at Old Lyme; Connecticut, in the year 1975. The affected group of patients was suffering with some uncommon symptoms of arthritis. By the ending of 1977 further 51 cases of "Lyme arthritis" were observed (Saccomano \& Hrelic, 2018). Lyme borreliosis (LB) or Lyme disease, is a developing and re-emerging tick borne disease caused primarily by Borrelia burgdorferi sensu stricto in Europe and North America by B. afzelii or B. garinii (Smith \& Thackinen, 2006; Bacon et al., 2008; Hubalek, 2009; Nelson et al., 2015; Schwartz et al., 2017; Sykes \& McIllo, 2017). The disease was mostly observed in similar climatic conditions of Scandinavia and Central Europe, the north eastern and Middle Western areas of United States as well as in some parts of Asia. The disease is reported to be Zoonotic and may be transmissible to humans through xodes ticks (Russell et al., 2018). Generally, B. burgdorferi is one of the most potent species causing joint infection, $B$. afzelii causes a typical skin infection, acrodermatitis chronic atrophicans (ACA) (Maraspin et al., 2019), and B. garinii most often causes neurological manifestations (Steere et al., 2016). Lyme disease is usually curable with treatment. If undiagnosed or incorrectly diagnosed may leads to debilitating conditions in patients. This may further enhance the cost of treatment (Mac et al., 2019).

Lyme disease has now attained public health concern worldwide. In Lyme (Connecticut) the affected children were found to be affected with juvenile rheumatoid arthritis (Van Hout, 2018). In humans, the disease is transmitted when ticks ingest the human blood which leads into the transformation of its further stage of development. While attaching to the human host; the ticks insert its hypostome into host skin. The Ixodes ticks secrets anticoagulants, anti-inflammatory as well as immunosuppressive chemicals which facilitates pathogen to enter into the host body (Carriveau et al., 2019).

The clinical symptoms of Lyme disease occur in stages (Steere, 1989). The majority of patients witness the development of the disease with erythema migrans which is a rash developing at the tick bite site. During early stage infection could be limited to the skin or spread through hematogenous route with inclusion of the skin, nervous system, heart or joints. Some untreated patients develop advanced stage disease within weeks or months, chiefly Lyme arthritis (Steere, 1989). Practically, most of the patients during early phase of disease could be treated with a short duration course of appropriate antibiotic regimen given orally, however the early stage of disease is not overt. In later stage, many persons could be treated successfully with antibiotic therapy yet a few patients do not respond to antibiotics, therefore require other management strategies (Steere \& Angelis, 2006; Arvikar \& Steere, 2015).

Diagnosis of LB is predicated absolutely on serological tests and PCR, yet establishing the diagnosis are often complicated especially at the early stages before the development of immunological response and for infection spreading to central nervous system, heart or joints. Moreover, downside of serological testing is that antibodies persist for quite a long time following infection. Moreover, scientists have sought to develop elective tests for serology, PCR and culture to accurately and timely diagnose and monitor the early and late stages of disease, even in people with explicit symptoms. The present review highlights the clinical manifestations, and advances in diagnosis and control of Lyme disease.

\section{Clinical Manifestations}

The clinical appearance of Lyme disease can be categorised in three stages to simplify its diagnostic procedure. Early localized stage is portrayed by erythema migrans at localized site of bite of tick. The subsequent stage strikes from weeks to months post-exposure and is manifested by multiple erythema migrans lesions, borreliol lymphocytoma, neuroboreliosis, carditis or infrequently Lyme arthritis. The third stage is characterized by acordermatitis chronic atrophicans, neurological symptoms and arthritis (Borchers et al., 2015). A second thought of the chronic form of $\mathrm{LD}$ is also prevalent among the research workers. They designate it as Post Lyme Syndrome which is also an inflammatory reaction phenomenon may be because of the persistence of the bacteria; probably due to Biofilm formation despite proper antibiotic therapy (Lacout et al., 2018). The existence of these signs and symptoms are species specific and differ between geographical regions.

\subsection{Cutaneous/Dermatologic manifestations}

There are mainly three characteristic skin manifestations which include erythema migrans, lymphocytoma and finally acrodermatitis chronica atrophicans (ACA). Erythema migrans appears in acute phase, whereas, lymphocytoma is a subacute manifestation and acrodermatitis is a chronic culminating manifestation in later stages of disease.

\subsection{Erythema migrans}

The most widely recognized form of Lyme borreliosis is erythema migrans, which extends from few days to few weeks with red or blue-red macular skin lesions (Bergland et al., 1995; Strel et al., 1996). Conversely, tick bite rashes develop from hours to days and usually fade in certain days. In young children, the most influenced areas are the neck and head; pelvic region or extremities in adults (Borchers et al., 2015). Systemic symptomatic presentation such as pain, fever and lymphadenopathy may occured along with erythema migrans. Just about portion of the individuals who experience the ill effects of erythema migrans recollect the tick bite. B. bergdorferi and B. garini often result in to homogeneous erythema migrans (Bennet et al., 2006a; Bennet et al., 2006b; Vasudevan \& Chatterjee, 2013). Lesions persevere from weeks to months if remain untreated (Steere et al., 1987; Miraflor et al., 2016).

\subsection{Borrelial lymphocytoma}

Borrelial lymphocytoma is an unusual cutaneous symptoms characterized by painless blue-red nodules and is principally observed in children (Vasudevan \& Chatterjee, 2013; Arnez \& Ruzic-Subljic, 
2015). Generally, borrelial lymphocytoma is apparent on the ear lobe, nipple or scrotum. There is usually a concomitant erythema migrans or is followed after a stage of erythema migrans (Berglund et al., 1995; Maraspin et al., 2016). Predominantly, B. afzelii causes borrelial lymphocytomas but $B$. burgdorferi and $B$. bissetti have also been reported (Maraspin et al., 2016). With antibiotics, borreliol lymphocytoma usually clears up within several weeks with treatment. Histopathology shows lymphocytic infiltration with plasma cells and germinal centres into the skin (Borchers et al., 2015). The differential diagnosis has a broad spectrum and comprises lymphomas, insect bites and sarcoidosis. Biopsy is often required in non-localized areas. The diagnosis can be affirmed by the historical backdrop of erythema migrans, serological tests, and molecular methods such as PCR organism culture or isolation on biopsy examination.

\subsection{Acrodermatitis chronica atrophicans}

Acrodermatitis chronic atrophicans is a cutaneous manifestation associated with late stage of Lyme disease that is generally reported in European countries and is chiefly caused by B. afzelii (Asbrink et al., 1986). ACA shows up as a chronic, gradually progressive reddish or bluish cutaneous lesion that may later on become atrophic (Asbrink \& Hovmark, 1988). ACA is the late manifestation of Lyme borreliosis and may last for months to years if untreated (Ogrinc et al., 2017). ACA has comparatively more prevalence in aged women and prefers the extensor surface of the distal extremities (Steer et al., 2016). Lesions start as edema with bluish-red plaques that gradually develop into atrophic and hyperpigmented plaques (Godar et al., 2015). Over half of patients report peripheral neuropathy equivalent to alodynia (Mullegger \& Glatz, 2008). ACA has been demonstrated to be unexpectedly resolved unlike other manifestations of Lyme borreliosis (Asbrink \& Howmark, 1988). Indeed, lesions more than 10 years of age may likewise be exposed to active infection by culture or PCR positivity and antimicrobial therapy responsive (Agterof \& ter Borg, 2008; Lenormand et al., 2016). The presence of typical symptoms similar to granuloma annular, lichen sclerosis or pseudolymphoma can interfere with the diagnosis. In addition, recent reports include newer clinical forms of the ACA, which could be spinous papules with erythema, small violaceous patches and foot tumour (Lenormand et al., 2016; Bauvin et al., 2017).

\subsection{Lyme neuroborreliosis (LNB) / Nervous system manifestations}

Borrelia spp. mainly affect skin, joints, nervous system or in some instances heart. Neurological form known as Lyme neuroboreliosis (LNB) have been accounted in one tenth of Lyme borreliosis cases (Bergland et al., 1995; Halperin, 2015). Early Lyme neuroboreliosis usually endures from days to weeks following a tick bite with lymphocytic meningitis, radiculoneuritis or cranial neuritis (Halperin, 2013; Koedel et al., 2015; Ogrinc et al., 2016). LNB is more common in children with facial nerve paralysis (Sodermark et al., 2017), whereas adults show radiculoneuritis and lymphocytic CSF pleocytosis (Hansen
\& Lebech, 1992; Koedel et al., 2015). CSF pleocytosis, intrathecal specific antibodies and neurological features help in the affirming the diagnosis of B. bergdorferi infection (Zajkowska et al., 2015).

\subsection{Lyme arthritis}

Lyme arthritis usually occurs as oligo or monoarthritis more frequently in the knee joint about three to six months post infection (Steere et al., 1987; Arvikar \& Steere, 2015). Lyme arthritis is less agonizing and is not accompanied by pyrexia unlike other causes of septic arthritis. Most of the patients do not report previous tick bites or erythema migrans. Manifestations can include intermittent or prolonged joint swelling and pain for months to years in untreated patients. Arthritis can be cured and borreliosis can be eradicated in most patients with proper antimicrobial treatment, in spite of the fact that at times proliferative synovitis may last for months to years together warranting anti inflammatory medicines (Arvikar \& Steere, 2015; Grillon et al., 2018). Anti-Borrelia antibodies detection, occurrence of erythema migrans earlier or detection by PCR in synovial fluid warrants appropriate therapy. Most of the arthritic patients could be cured by appropriate antibiotic therapy and nonsteroidal anti-inflammatory drugs (Mullegger \& Glatz, 2008). These complex cases may benefit from treatment by methotrexate and hydroxychloroquine like other chronic inflammatory arthritis (Arvikar \& Steere, 2015).

\subsection{Lyme carditis / cardiovascular manifestations}

Acute cardiovascular inclusion may happen, which is portrayed by varying degrees of atrioventricular conduction defects in early disseminated infection (Lelovas et al., 2008; Steere et al., 2016). Some of the infrequent cardiac manifestations could include cardiomyopathy and acute myopericarditis. The Lyme carditis may also be manifested with several other conditions like acute myocarditis, pericarditis, myopericarditis, endocarditis, and pancarditis. Such conditions may leads to the reduced left ventricular cardiac functions. The Acute Coronary Syndrome may mimic with the Lyme myopericarditis (Yeung \& Baranchuk, 2019). The most frequent manifestations in patients having Lyme borreliosis with involvement of the heart are Atrioventricular Conduction disorder or other rhythm disorders, myocarditis, pericarditis, Postural Orthostatic Tachycardia Syndrome (POTS) (Trevisan et al., 2020). Lyme carditis is often self-limiting yet might be fatal if there is no treatment (Robinson et al., 2015; Scheffold et al., 2015).

\section{Diagnosis and Advancements in Diagnosis}

Diagnosis may be possible by isolation and identification of $B$. burgdorferi from the lesions of erythema migrans and the blood of affected persons especially during early stages (Steere et al., 2016). Center for Disease Control has recommended a two step assay. The first step starts with, the enzyme immunoassay or immunofluorescence assay. The positive assay of this test is subjected to Western blot analysis (CDC, 1995). Erythema migrans 
can be diagnosed dependent on clinical outcomes including exhibited or suspected tick bites or local site exposure. The IgM isotype is positive in one-fifth to half of cases in the initial two to three weeks and $\mathrm{IgG}$ is positive in one to two months post infection (Steere et al., 2016). Borrelial lymphocytoma diagnosis is upheld with positive serological results. Histopathology could be helpful in the diagnosis and is regularly done to differentiate from other conditions. Moreover, biopsy sample analysis by PCR or culture confirms the diagnosis, in spite of the fact that the sensitivity of these tests is highly variable. ACA is characterized by high-titer serum IgG antibodies. Although, high-titer tests are usually adequate; histopathological analysis, PCR or tissue culture may help in diagnosis (Stanek et al., 2011). Lyme arthritis with hightiter IgG provides Borrelia antibodies. The two-tier analysis approach is extremely useful and sensitive (Shapiro, 2014). To confirm Lyme neuroborreliosis (LNB) diagnosis specific clinical manifestations along with intrathecal specific antibody production are authentic parameters. Cerebrospinal fluid (CSF) pleocytosis is quite often present. Blood and CSF ought to be analyzed for antibody detection and profiling with the demonstration of central nervous system (CNS) antibody production. In early stages of $\mathrm{LNB}$, intrathecal $\mathrm{IgG}$ is positive 6 to 8 weeks before the onset of symptoms (Stanek et al., 2011). Culture and PCR have low yields in LNB but could be helpful for diagnosing early antibody negative cases. The new biomarker chemokine CLCX13 has additionally shown a promise, however, its application has not been recommended so far.

There are limited reports of cultural isolation from synovial fluid however, B. burgdorferi DNA could be detected in synovial fluid by PCR and also with lesser reliability from the CSF (Steere et al., 2016). In Europe, for the diagnosis of Lyme neuroboreliosis, testing for intrathecal antibody production is comprehensive where multiple Borrelia spp. and high seroprevalence limit the use of serological analysis (Stanek et al., 2012). Two-tier serological analysis is the diagnostic test of choice in most cases of LNB (Aguero-Rosenfeld et al., 2005; Wormser et al., 2005; Wormser et al., 2006). Adjunctive testing for intrathecal antibody production is quite specific in diagnosing the disease especially in endemic regions. When testing for intrathecal antibodies, it is imperative to observe that in some patients with Lyme disease, antibodies in the serum are passively transferred to the CSF (Steere et al., 1990). To check this transfer, CSF and serum should be collected simultaneously and the concentration of total protein or IgG should be matched.

The novel ELISA technique; capable to detect early IgG in suffering suspected patients of Erythema migrans, is under development. The availability of ELISA test using C6 peptide as an antigen of VIsE lipoproteins of B. burgdorferi was found to be useful because of its higher sensitivity for B. afzelii and B. garinii (Bush \& VazquezPertejo, 2018).
PCR provides unique evidence of $B$. bergdorferi nucleic acid in diverse samples including skin biopsy, synovial fluid, blood and CSF (Babady et al., 2008). Though, its clinical utility is restricted due to its low sensitivity and its vulnerability for contamination (Molloy et al., 2015). Synovial fluid PCR is highly sensitive to Lyme arthritis and can be used in combination with other synovial fluid analyses to make a differential diagnosis of Lyme arthritis from other arthritis (Babady et al., 2008). Comparatively, the PCR of CSF is significantly less sensitive limiting its clinical applicability. The PCR trials of CSF gave positive outcomes with early neuroboreliosis but less sensitive to late neuroboreliosis (Nocton et al., 1996). PCR for Lyme Diagnosis is not universally standardized or optimized. PCR of blood demonstrated the utility in identifying the novel genus B. miyamotoi and B. mayonii (Molloy et al., 2015). Detection by PCR is accomplished by amplification of selected genes: 16S rRNA gene, 23S rRNA gene, the 5S rRNA-23S rRNA gene spacer, p66, fla, recA and ospA (Aguero-Rosenfeld et al., 2005). Genotyping and quantification of Borrelia can be made from skin biopsies using real-time PCR (Liveris et al., 2012; O'Rourke et al., 2013). The strengths of PCR assays in skin samples are due to its high sensitivity, rapidity and direct detection from the original biopsy sample. However, the identification of Borrelia DNA does not generally indicate an active or concurrent infection and DNA can be detected at least in mouse specimens after antibiotic treatment (Grillon et al., 2017). Since B. bergdorferi is a slowgrowing organism, therefore, cultural methods are cumbersome and less sensitive and therefore, are not generally recommended (AgueroRosenfeld et al., 2005).

In future, direct techniques for culture, detection of borreliol antigens, specific nucleic acid detection and genetic sequencing could gain importance (Ruzic-Sabljic \& Cerar, 2017; Branda et al., 2018; Schutzer et al., 2019). At present, validated diagnostic test for confirmatory diagnosis of $B$. burgdorferi is antibody response to confirm the diagnosis of Lyme disease (Marques, 2015; Theel, 2016). A two-step assay based on the initial ELISA was developed which was followed by Western blot testing for IgM as well as IgG antibodies to increase sensitivity and specificity during various phases and in different forms of Lyme disease (Alasel \& Keusgen, 2018). In recent times, the Food and Drug Administration (FDA) approved EIA tests which target the specific immune response against the cell surface variable majorprotein-like sequenced expressed (VlsE) along with its sixth invariable region, C6 peptide. These simple tests replace western blot testing (Schoen, 2013). However, the persistent problem is serological overtesting, misinterpretation of tests and over-diagnosis (Webber et al., 2019; Markowicz et al., 2015; Lantos et al., 2015).

Few more rapid diagnostic testing (RDT) are available, of those the important two are: immunochromatography based tests and microfluidic based tests. In Europe, immunochromatography based methods are economically accessible in clinical laboratories and for self use. These RDTs are simple and require no exhaustive specialized training. However, the RDT performance is yet to 
evaluate fully, moreover, regulations for these tests are also are not available till date (Smith et al., 2014). Another test, the microfluidbased rapid point-of-care test, which could provide results within 15 minutes, is yet to be made available in market (Nayak et al., 2016). This test was $84 \%$ sensitive and $92 \%$ specific in comparison to laboratory-based C6-peptide ELISA, but less sensitive than recombinant ELISA (Nayak et al., 2016). Alternative diagnostic tools are needed to confirm the active cases. Recently, xenodiagnosis with live ticks has been tested to know the effectiveness of antibiotic therapy (Marques et al., 2014). However, live larval ticks may induce strong itching reactions in some patients, so may be used with due caution. Alternative diagnostic tools are required to identify live forms of Borrelia. Mass spectrometry could directly detect pathogenic proteins in the skin. The use of proteomics in the skin has been successfully done, especially in punch biopsy in psoriasis patients (Lundberg et al., 2015) or in patients with keratome biopsy to reduce cellular complication (Williamson et al., 2013).

\section{Treatment, Prevention and Control}

The most of the cases of neuroborreliosis are curable with time; without treatment. The antibiotics under use, helps further in the clearance of bacteria from the host affected and stop further spread of the disease. This reduces the losses of axonal degeneration. Penicillin G, Doxycycline, Ceftriaxone, Cefotaxime etc are some antibiotics which were found to be effective in early neuroborreliosis. The uses of steroids are also not been reported in neuroborreliosis (Russell et al., 2018). Doxycycline is the widely used antimicrobial in early stage of Lyme Disease. Minocycline is an alternative second choice of drug (Carriveau et al., 2019). An openlabel randomized controlled trial was conducted to evaluate the efficacy of single dose doxycycline therapy following tick bite to prevent the development of Lyme borreliosis (Harms et al., 2020). The findings indicate that administering a single dose of doxycycline (200 mg) within 72 hours can prevent the development of Lyme borreliosis following Ixodes ricinus tick bite. Although, Lyme borreliosis generally responds very well to antibiotic therapy, patients may develop persistent symptoms, most commonly referred to as chronic Lyme (Kullberg et al., 2020). These symptoms include pain, fatigue, and neurocognitive symptoms that can persist and at the same time highly disabling.

The best prevention for the Lyme disease is to avoid to move in tick infested areas; the areas of tall grasses, shady and moist. Such lands may be of higher risk for infections. If the movements in such areas are unavoidable then one should wear the cloths which fully cover their body, light colored cloths which are less attractive for ticks. People also use diethyltoluamide, commonly named as DEET which works as insects repellent.

At present there is no human Lyme disease vaccine available. Although several attempts have been made to develop a vaccine, none have been successfully marketed. Proteomic approach has been applied to identify vaccine candidates for Lyme disease from skin biopsies in a mouse model. A total of 30 bacterial proteins were identified after syringe inoculation or tick inoculation of bacteria. Therefore, further investigations should be conducted to define the role of each protein in the elaboration of protective immunity (Talagrand-Reboul et al., 2020). Recently, structure-based surface shaping approach was used for the development of vaccine against Lyme borreliosis. The proposed multivalent outer surface protein A (OspA) vaccine is expected to target wide range of pathogenic Borrelia species with the help of a single recombinant antigen thereby offering an efficient preventive strategy against Lyme borreliosis (Nayak et al., 2020).

\section{Conclusions and Way Forward}

Lyme disease has gained renewed importance during last two decades. The disease is always a suspect in endemic areas and can be successfully diagnosed, monitored and treated. However, diagnosis is a problem in areas where the disease has very low prevalence especially due to lack of knowledge about this disease and its manifestations. Skin afflictions are early symptoms of Lyme disease which could eventually lead to arthritis, neurological and cardiac forms in due course. Additionally, PCR, serology and some more diagnostic assays are developed, but their validation or assessment is yet incomplete. More focused research is required to find out their sensitivity, specificity and reproducibility. Identification of new biomarkers to rapidly confirm the disease could be a major breakthrough in its diagnosis and subsequent control of active Borrelia infection and could prove to be a major advancement in LB diagnosis and monitoring.

\section{Author contributions}

All the authors substantially contributed to the conception, compilation of data, checking and approving the final version of the manuscript, and agree to be accountable for its contents.

\section{Acknowledgments}

All the authors acknowledge and thank their respective Institutes and Universities.

\section{Funding}

This compilation is a review article written by its authors and required no substantial funding to be stated.

\section{Disclosure statement}

All authors declare that there exist no commercial or financial relationships that could, in any way, lead to a potential conflict of interest. 


\section{References}

Agterof MJ, ter Borg EJ (2008) Erythematous pigmentation of the arm for more than ten years. Netherlands Journal of Medicine 66:176-179.

Aguero-Rosenfeld ME, Wang G, Schwartz I, Wormser GP (2005) Diagnosis of Lyme borreliosis. Clinical Microbiology Reviews 18:484-509.

Alasel M, Keusgen M (2018) Promising alternatives for one-tier testing of Lyme borreliosis. Clinica Chimica Acta 479:148-154.

Arnez M, Ruzic-Sabljic E (2015) Borrelial lymphocytoma in children. Pediatric Infectious Disease Journal 34:1319-1322.

Arvikar SL, Steere AC (2015) Diagnosis and treatment of Lyme arthritis. Infectious Disease Clinics of North America 29:269-280.

Asbrink E, Hovmark A (1988) Early and late cutaneous manifestations in Ixodes-borne borreliosis (erythema migrans borreliosis, Lyme borreliosis). Annals of the New York Academy of Sciences 539:4-15.

Asbrink E, Hovmark A, Olsson I (1986) Clinical manifestations of acrodermatitis chronica atrophicans in 50 Swedish patients. Zentralbl Bakteriol Mikrobiol Hyg A 263:253-261.

Babady NE, Sloan LM, Vetter EA, Patel R, Binnicker MJ (2008) Percent positive rate of Lyme real-time polymerase chain reaction in blood, cerebrospinal fluid, synovial fluid, and tissue. Diagnostic Microbiology and Infectious Disease 62:464-466.

Bacon RM, Kugeler KJ, Mead PS, Centers for Disease C Prevention (2008) Surveillance for Lyme disease--United States, 1992-2006. The Morbidity and Mortality Weekly Report (MMWR) Surveillance Summaries 57(10):1-9.

Bauvin O, Schmutz JL, De Martino S, Busato T, Cribier B, Barbaud A, Wahl D, Bursztejn AC (2017) A foot tumour as late cutaneous Lyme borreliosis: a new entity? British Journal of Dermatology 177(4):1127-1130.

Bennet L, Fraenkel CJ, Garpmo U, Halling A, Ingman M, Ornstein K, Stjernberg L, Berglund J (2006a) Clinical appearance of erythema migrans caused by Borrelia afzelii and Borrelia garinii-effect of the patient's sex. Wiener klinische Wochenschrift 118:531-537.

Bennet L, Halling A, Berglund J (2006b) Increased incidence of Lyme borreliosis in southern Sweden following mild winters and during warm, humid summers. European Journal of Clinical Microbiology \& Infectious Diseases 25:426-432.

Berglund J, Eitrem R, Ornstein K, Lindberg A, Ringnér Å, Elmrud H, Carlsson M, Runehagen A, Svanborg C, Norrby R (1995) An epidemiologic study of Lyme disease in southern Sweden. New England Journal of Medicine 333:1319-1324.
Borchers AT, Keen CL, Huntley AC, Gershwin ME (2015) Lyme disease: a rigorous review of diagnostic criteria and treatment. Journal of Autoimmunity 57:82-115.

Branda JA, Body BA, Boyle J, Branson BM, Dattwyler RJ, Fikrig E, Gerald NJ, Gomes-Solecki M, Kintrup M, Ledizet M, Levin AE (2018) Advances in serodiagnostic testing for Lyme disease are at hand. Clinical Infectious Disease 66(7):1133-1139.

Bush LM, Vazquez-Pertejo MT (2018) Tick borne illness-Lyme disease. Disease-a-Month 64(5):195-212. doi: 10.1016/j.disamonth.2018.01.007.

Carriveau A, Poole H, Thomas A (2019) Lyme disease. Nursing Clinics of North America 54: 261-275 https://doi.org/10.1016/j.cnur.2019.02.003.

CDC (1995) MMWR Morbidity and mortality weekly report. Recommendations for test performance and interpretation from the Second National Conference on Serologic Diagnosis of Lyme Disease. Accessed on 10 July 2018.

Godar DA, Laniosz V, Wetter DA (2015) Lyme disease update for the general dermatologist. American Journal of Clinical Dermatology 16:5-18.

Grillon A, Scherlinger M, Boyer PH, De Martino S, Perdriger A, Blasquez A, Wipff J, Korganow AS, Bonnard C, Cantagrel A, Eyer D (2018) Characteristics and clinical outcomes after treatment of a national cohort of PCR-positive Lyme arthritis. Seminars in Arthritis and Rheumatism 48:1105-1112.

Grillon A, Westermann B, Cantero P, Jaulhac B, Voordouw MJ, Kapps D, Collin E, Barthel C, Ehret-Sabatier L, Boulanger N (2017) Identification of Borrelia protein candidates in mouse skin for potential diagnosis of disseminated Lyme borreliosis. Scientific Reports 7:16719.

Halperin JJ (2013) Nervous system Lyme disease: diagnosis and treatment. Current Treatment Options in Neurology 15:454-464.

Halperin JJ (2015) Nervous system Lyme disease. Infectious Disease Clinics of North America 29(2):241-253.

Hansen K, Lebech AM (1992) The clinical and epidemiological profile of Lyme neuroborreliosis in Denmark 1985-1990. Brain 115:399-423.

Harms MG, Hofhuis A, Sprong H, Bennema SC, Ferreira JA, Fonville M, Docters van Leeuwen A, Assendelft WJJ, Van Weert HCPM, Van Pelt W, Van den Wijngaard CC (2020) A single dose of doxycycline after an Ixodes ricinus tick bite to prevent Lyme borreliosis: an openlabel randomized controlled trial. Journal of Infection S01634453(20)30414-X. 
Hubalek Z (2009) Epidemiology of lyme borreliosis. Current Problems in Dermatology 37:31-50.

Koedel U, Fingerle V, Pfister HW (2015) Lyme neuroborreliosisepidemiology, diagnosis and management. Nature Reviews Neurology 11:446-456.

Kullberg BJ, Vrijmoeth HD, van de Schoor F, Hovius JW (2020) Lyme borreliosis: diagnosis and management. British Medical Journal 369:m1041. doi: 10.1136/bmj.m1041.

Lacout A, Thariat J, Hajjam ME, Marcy PY, Perronne C (2018) Lyme disease \& co-infections: role of adaptive immune system. Future Microbiology 13:613-615. doi: 10.2217/fmb-2017-0252.

Lantos PM, Branda JA, Boggan JC, Chudgar SM, Wilson EA, Ruffin F, Fowler V, Auwaerter PG, Nigrovic LE (2015) Poor positive predictive value of Lyme disease serologic testing in an area of low disease incidence. Clinical Infectious Disease 61:1374-1380.

Lelovas P, Dontas I, Bassiakou E, Xanthos T (2008) Cardiac implications of Lyme disease, diagnosis and therapeutic approach. International Journal of Cardiology 129:15-21.

Lenormand C, Jaulhac B, Debarbieux S, Dupin N, Granel-Brocard F, Adamski H, Barthel C, Cribier B, Lipsker D (2016) Expanding the clinicopathological spectrum of late cutaneous Lyme borreliosis (acrodermatitis chronic atrophicans (ACA)): a prospective study of 20 culture- and/or polymerase chain reaction (PCR)-documented cases. Journal of the American Academy of Dermatology 74:685-692.

Liveris D, Schwartz I, McKenna D, Nowakowski J, Nadelman R, DeMarco J, Iyer R, Bittker S, Cooper D, Holmgren D, Wormser GP (2012) Comparison of five diagnostic modalities for direct detection of Borrelia burgdorferi in patients with early Lyme disease. Diagnostic Microbiology and Infectious Disease 73:243-245.

Lundberg KC, Fritz Y, Johnston A, Foster AM, Baliwag J, Gudjonsson JE, Schlatzer D, Gokulrangan G, McCormick TS, Chance MR, Ward NL (2015) Proteomics of skin proteins in psoriasis: from discovery and verification in a mouse model to confirmation in humans. Molecular \& Cellular Proteomics 14:109-119.

Mac S, da Silva SR, Sander B (2019) The economic burden of Lyme disease and the cost effectiveness of Lyme disease interventions: A scoping review. PLoS ONE 14(1): e0210280.

Maraspin V, Mrvic T, Ruzic-Sabljic E, Jurčić V, Strle, F (2019) Acrodermatitis chronica atrophicans in children: report on two cases and review of the literature. Ticks and Tick-borne Diseases 10:180-185.

Maraspin V, Nahtigal Klevisar M, Ruzic-Sabljic E, Lusa L, Strle F (2016) Borrelial lymphocytoma in adult patients. Clinical Infectious Diseases 63:914-921.
Markowicz M, Kivaranovic D, Stanek G (2015) Testing patients with nonspecific symptoms for antibodies against Borrelia burgdorferi sensu lato does not provide useful clinical information about their aetiology. Clinical Microbiology and Infection 21:1098-1103.

Marques A, Telford SR, Turk SP, Chung E, Williams C, Dardick K, Krause PJ, Brandeburg C, Crowder CD, Carolan HE, Eshoo MW (2014) Xenodiagnosis to detect Borrelia burgdorferi infection: a firstin-human study. Clinical Infectious Disease 58:937-945.

Marques AR (2015) Laboratory diagnosis of Lyme disease: advances and challenges. Infectious Disease Clinics of North America 29:295307.

Miraflor AP, Seidel GD, Perry AE, Castanedo-Tardan MP, Guill MA, Yan S (2016) The many masks of cutaneous Lyme disease. Journal of Cutaneous Pathology 43:32-40.

Molloy PJ, Telford SR III, Chowdri HR, Lepore TJ, Gugliotta JL, Weeks KE, Hewins ME, Goethert HK, Berardi VP (2015) Borrelia miyamotoi disease in the northeastern United States: a case series. Annals of Internal Medicine 163:91-98.

Mullegger RR, Glatz M (2008) Skin manifestations of Lyme borreliosis: diagnosis and management. American Journal of Clinical Dermatology 9:355-368.

Nayak A, Schüler W, Seidel S, Gomez I, Meinke A, Comstedt P, Lundberg U (2020) Broadly Protective Multivalent OspA Vaccine against Lyme Borreliosis, Developed Based on Surface Shaping of the C-Terminal Fragment. Infection and Immunity 88(4):e00917-19.

Nayak S, Sridhara A, Melo R, Richer L, Chee NH, Kim J, Linder V, Steinmiller D, Sia SK, Gomes-Solecki M (2016) Microfluidics-based point-of-care test for serodiagnosis of Lyme disease. Scientific Reports 6:35069.

Nelson CA, Saha S, Kugeler KJ, Delorey MJ, Shankar MB, Hinckley $\mathrm{AF}$, Mead PS (2015) Incidence of Clinician-Diagnosed Lyme Disease, United States, 2005-2010. Emerging Infectious Diseases 21(9):16251631.

Nocton JJ, Bloom BJ, Rutledge BJ, Persing DH, Logigian EL, Schmid CH, Steere AC (1996) Detection of Borrelia burgdorferi DNA by polymerase chain reaction in cerebrospinal fluid in Lyme neuroborreliosis. Journal of Infectious Diseases 174:623-627.

O'Rourke M, Traweger A, Lusa L, Stupica D, Maraspin V, Barrett PN, Strle F, Livey I (2013) Quantitative detection of Borrelia burgdorferi sensu lato in erythema migrans skin lesions using internally controlled duplex real time PCR. PLoS One 8:63968.

Ogrinc K, Lusa L, Lotric-Furlan S, Bogovič P, Stupica D, Cerar T, Ružić-Sabljić E, Strle F (2016) Course and outcome of early European 
Lyme neuroborreliosis (Bannwarth Syndrome): clinical and laboratory findings. Clinical Infectious Diseases 63:346-353.

Ogrinc K, Wormser GP, Visintainer P, Maraspin V, Lotrič-Furlan S, Cimperman J, Ružić-Sabljić E, Bogovič P, Rojko T, Stupica D, Strle F (2017) Pathogenetic implications of the age at time of diagnosis and skin location for acrodermatitis chronica atrophicans. Ticks and Tickborne Diseases 8:266-269.

Robinson ML, Kobayashi T, Higgins Y, Calkins H, Melia MT (2015) Lyme carditis. Infectious Disease Clinics of North America 29:255268.

Russell ALR, Dryden MS, Pinto AA, Lovett JK (2018) Lyme Disease: diagnosis and management. Practical Neurology 18(6):1-10. doi:10.1136/practneurol-2018-001998.

Ruzic-Sabljic E, Cerar T (2017) Progress in the molecular diagnosis of Lyme disease. Expert Review of Molecular Diagnostics 17:19-30.

Saccomano SJ, Hrelic DA (2018) Recognizing and treating Lyme disease. Nurse Practitioner 43(8):13-21. doi: 10.1097/01.NPR.0000541469.54290.00.

Scheffold N, Herkommer B, Kandolf R, May AE (2015) Lyme carditis-diagnosis, treatment and prognosis. Deutsches Ärzteblatt International 112:202-208.

Schoen RT (2013) Editorial commentary: better laboratory testing for Lyme disease: no more western blot. Clinical Infectious Diseases 57:341-343.

Schutzer SE, Body BA, Boyle J, Branson BM, Dattwyler RJ, Fikrig E, Gerald NJ, Gomes-Solecki M, Kintrup M, Ledizet M, Levin AE (2019) Direct diagnostic tests for Lyme disease. Clinical Infectious Diseases 68:1052-1057.

Schwartz AM, Hinckley AF, Mead PS, Hook SA, Kugeler KJ (2017) Surveillance for Lyme diseasedUnited States, 2008-2015. The Morbidity and Mortality Weekly Report (MMWR) Surveillance Summaries 66:1-12.

Shapiro ED (2014) Lyme disease. New England Journal of Medicine 370(18):1724-1731.

Smit PW, Kurkela S, Kuusi M, Vapalahti O (2014) Evaluation of two commercially available rapid diagnostic tests for Lyme borreliosis. European Journal of Clinical Microbiology \& Infectious Diseases 34:109-113.

Smith R, Takkinen J (2006) Lyme borreliosis: Europe-wide coordinated surveillance and action needed? Eurosurveillance 11(6):E0606221
Sodermark L, Sigurdsson V, Nas W, Wall P, Trollfors B (2017) Neuroborreliosis in Swedish children: a population-based study on incidence and clinical characteristics. Pediatric Infectious Disease Journal 36:1052-1056.

Stanek G, Fingerle V, Hunfeld KP, Jaulhac B, Kaiser R, Krause A, Kristoferitsch W, O'connell S, Ornstein K, Strle F, Gray J (2011) Lyme borreliosis: clinical case definitions for diagnosis and management in Europe. Clinical Microbiology and Infection 17:69-79.

Stanek, G, Wormser, GP, Gray J, Strle F (2012) Lyme borreliosis. The Lancet 379(9814):461-473.

Steere AC (1989) Lyme disease. New England Journal of Medicine 321:586-596.

Steere AC, Angelis SM (2006) Therapy for Lyme arthritis: strategies for the treatment of antibiotic-refractory arthritis. Arthritis \& Rheumatology 54:3079-3086.

Steere AC, Berardi VP, Weeks KE, Logigian EL, Ackermann R (1990) Evaluation of the intrathecal antibody response to Borrelia burgdorferi as a diagnostic test for Lyme neuroborreliosis. Journal of Infectious Diseases 161(6):1203-1209.

Steere AC, Schoen RT, Taylor E (1987) The clinical evolution of Lyme arthritis. Annals of Internal Medicine 107:725-731.

Steere AC, Strle F, Wormser GP, Hu LT, Branda JA, Hovius JW, Li X, Mead PS (2016) Lyme borreliosis. Nature Reviews Disease Primers 2:16090.

Strle F, Nelson JA, Ruzic-Sabljic E, Cimperman J, Maraspin V, LotricFurlan S, Cheng Y, Picken MM, Trenholme GM, Picken RN (1996) European Lyme borreliosis: 231 culture-confirmed cases involving patients with erythema migrans. Clinical Infectious Diseases 23:61-65.

Sykes RA, Makiello P (2017) An estimate of Lyme borreliosis incidence in Western Europey. Journal of Public Health 39:74-81.

Talagrand-Reboul E, Westermann B, Raess MA, Schnell G, Cantero P, Barthel C, Ehret-Sabatier L, Jaulhac B, Boulanger N (2020) Proteomic as an Exploratory Approach to Develop Vaccines Against Tick-Borne Diseases Using Lyme Borreliosis as a Test Case. Vaccines (Basel) $8(3): 463$.

Theel ES (2016) The past, present, and (possible) future of serologic testing for Lyme disease. Journal of Clinical Microbiology 54:11911196.

Trevisan G, Bonin S, Ruscio M (2020) A Practical Approach to the Diagnosis of Lyme Borreliosis: From Clinical Heterogeneity to Laboratory Methods. Front Med (Lausanne). 7:265.

Journal of Experimental Biology and Agricultural Sciences http://www.jebas.org 
Van Hout MC (2018) The Controversies, Challenges and Complexities of Lyme Disease: A Narrative Review. Journal of Pharmacy and Pharmaceutical Sciences 21(1):429-436. doi: 10.18433/jpps30254.

Vasudevan B, Chatterjee M (2013) Lyme borreliosis and skin. Indian Journal of Dermatology 58(3):167-174.

Webber BJ, Burganowski RP, Colton L, Escobar JD, Pathak SR, Gambino-Shirley KJ (2019) Lyme disease overdiagnosis in a large healthcare system: a population-based, retrospective study. Clinical Microbiology and Infection 25:1233-1238.

Williamson JC, Scheipers P, Schwämmle V, Zibert JR, Beck HC, Jensen ON (2013) A proteomics approach to the identification of biomarkers for psoriasis utilising keratome biopsy. Journal of Proteomics 94: 176-185.

Wormser GP, Dattwyler RJ, Shapiro ED, Halperin JJ, Steere AC, Klempner MS, Krause PJ, Bakken JS, Strle F, Stanek G, Bockenstedt L
(2006) The clinical assessment, treatment, and prevention of Lyme disease, human granulocytic anaplasmosis, and babesiosis: clinical practice guidelines by the Infectious Diseases Society of America. Clinical Infectious Diseases 43(9):1089-1134.

Wormser GP, McKenna D, Carlin J, Nadelman RB, Cavaliere LF, Holmgren D, Byrne DW, Nowakowski J (2005) Brief communication: hematogenous dissemination in early Lyme disease. Annals of Internal Medicine 142(9):751-755.

Yeung C, Baranchuk A (2019) Diagnosis and Treatment of Lyme Carditis: JACC Review Topic of the Week. Journal of the American College of Cardiology 73(6):717-726. doi: 10.1016/j.jacc.2018.11.035. Erratum in: Journal of the American College of Cardiology 2019 74(21):2709-2711.

Zajkowska J, Garkowski A, Moniuszko A, Czupryna P, PtaszynskaSarosiek I, Tarasow E, Ustymowicz A, Łebkowski W, Pancewicz S (2015) Vasculitis and stroke due to Lyme Lyme neuroborreliosis-a review. Infectious Diseases 47(1):1-6. 